\title{
Heat Transfer in a Thin Liquid Film in the Presence of an Electric Field
}

\author{
Rama Subba Reddy Gorla \\ Cleveland State University \\ Jorge E. Gatica \\ Cleveland State University \\ Bahman Ghorashi \\ Cleveland State University \\ Follow this and additional works at: https://engagedscholarship.csuohio.edu/encbe_facpub \\ diann Ineyrthe Chemical Engineering Commons \\ Cleveland State University \\ How does access to this work benefit you? Let us know! \\ Rautins/ards Statement

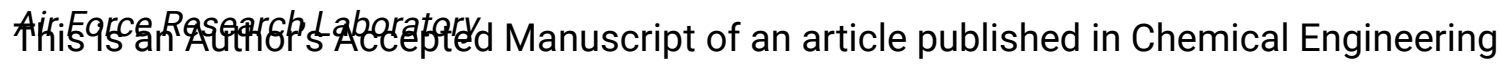 \\ Communications May 2004, available online: http://www.tandfonline.com/10.1080/ \\ 00986440490276038
}

\section{Original Citation}

Gorla, R., Gatica, J. E., Ghorashi, B., Ineure, P., \& Byrd, L. W. (2004). HEAT TRANSFER IN A THIN LIQUID

FILM IN THE PRESENCE OF AN ELECTRIC FIELD. Chemical Engineering Communications, 191(5),

718-731.

\section{Repository Citation}

Gorla, Rama Subba Reddy; Gatica, Jorge E.; Ghorashi, Bahman; Ineure, Pijarn; and Byrd, Larry W., "Heat Transfer in a Thin Liquid Film in the Presence of an Electric Field" (2004). Chemical \& Biomedical Engineering Faculty

Publications. 47.

https://engagedscholarship.csuohio.edu/encbe_facpub/47

This Article is brought to you for free and open access by the Chemical \& Biomedical Engineering Department at EngagedScholarship@CSU. It has been accepted for inclusion in Chemical \& Biomedical Engineering Faculty Publications by an authorized administrator of EngagedScholarship@CSU. For more information, please contact library.es@csuohio.edu. 


\section{HEAT TRANSFER IN A THIN LIQUID FILM IN THE PRESENCE OF AN ELECTRIC FIELD}

\section{RAMA SUBBA REDDY GORLA}

Department of Mechanical Engineering, Cleveland State University, Cleveland, Ohio, USA

JORGE E. GATICA

BAHMAN GHORASHI

PIJARN INEURE

Department of Chemical Engineering, Cleveland State

University, Cleveland, Ohio, USA

\section{LARRY W. BYRD}

Thermal Structures Branch, Air Vehicles Directorate, Air Force Research Laboratory, Wright Patterson Air Force Base, Ohio, USA

Heat transfer enhancement in an evaporating thin liquid film utilizing a electric field under isothermal interfacial condition is presented. A new mathematical model subjected to van der Waals attractive forces, capillary pressure, and an electric field is developed to describe the heat transfer enhancement in the evaporating thin liquid film. The effect of the electrostatic field on the curvature of the thin film, evaporative flux, pressure gradient distribution, heat flux, and heat transfer coefficient in the thin film is presented. The results show that applying an electric field can enhance heat transfer in a thin liquid film significantly. In addition, utilizing electric fields on the evaporating film will be a way to expand the extended meniscus region to attain high heat transfer coefficients and high rates of heat flux. 
Keywords: Thin films; Evaporating films; Heat transfer; Electric field; Disjointing pressure; Capillary action

\section{INTRODUCTION}

Active techniques of heat transfer enhancement in single phase and phasechange processes by utilizing electric fields have been the subject of intensive research during recent years. In much of a thin film, the resistance to heat transfer is principally by conduction through the film, which leads to the conclusion that the thinner the film the higher the resultant heat transfer. In addition, evaporation of thin liquid films has been recognized for some time as a means of achieving high heat transfer coefficients and high heat flux densities. Thus, techniques that employ this mechanism have significant potential for use in a number of technical applications such as heat pipes and heat exchangers. One way of creating such a thin film is to encourage the formation of an extended meniscus at the location where a liquid-free surface would be in contact with a solid wall.

Heat transfer enhancement by applying an electric field has been studied theoretically and experimentally (Lykoudis and Yu 1963; Turnbull, 1971; Lazarenko et al., 1975, Berghmans, 1976; Jones, 1978; Yabe, 1991, 1995; Maekawa, et al., 1992; Takano et al., 1994; Neve and Yan, 1996; Zaghdoudi and Lallemand, 1999). These results showed that application of an electric field could immensely enhance heat transfer. Additionally, evaporation from the extended meniscus in a thin liquid film has also be widely investigated theoretically and experimentally (Potash and Wayner, 1972, Edwards et al., 1974; Wayner et al., 1976; Renk et al., 1978; Holm and Goplen, 1979; Moosman and Homsy, 1980; Truong and Wayner, 1987; Mirzamoghadam and Catton, 1988; Wayner, 1989, 1994; Yu and Carey, 1990; Tao and Kaviany, 1991; Dussan et al., 1991; Stephan and Busse, 1992; Swanson and Peterson, 1994; Schonberg and Wayner, 1992; Chebaro et al., 1992, 1993, 1994; Chebaro and Hallinan, 1993; Moctar et al., 1993, Dasgupta et al., 1993, 1994; Brown et al., 1993, Swanson and Herdt, 1992; Khrustalev and Faghri, 1995; Kim and Wayner, 1996; Ha and Peterson, 1998; Voinov, 1998; Hopkins et al., 1999; Pismen et al., 2000). Many mathematical models have been presented to clarify evaporation and heat transfer in the extended meniscus region of a thin film under diverse limitations.

Heat transfer enhancement in thin liquid film by utilizing electric fields has not been addressed yet. Therefore, the present study was undertaken in order to clarify heat transfer enhancement in thin liquid film by utilizing an electric field. Numerical solutions are presented for a new mathematical model that combines the effects of capillary pressure, van der Waals attraction forces, and an electric field to evaluate the behavior of heat transfer in a thin liquid film. 


\section{ANALYSIS}

The effect of an electrostatic field on a thin liquid film between the adsorbed film and the meniscus of an evaporating interface is studied by extending the theoretical treatment developed by Chebaro et al. (1992, 1993, 1994) Chebaro and Hallinan (1993). The frame of reference is considered in rectangular coordinates with the $x$-axis along the wall and the $y$-axis normal to the wall as depicted in Figure 1, where $x=0$ at the connection of the adsorbed film with the thin film.

The augmented Young-Laplace equation (Dasgupta et al., 1993) is modified to account for the disjoining and capillary pressure and electrostatic field present in curved evaporating thin liquid film as the following expression:

$P_{v}-P_{\ell}=\psi+\sigma K+\Im$

where $P_{\ell}$ is the liquid pressure, $P_{v}$ is the vapor phase pressure, $\psi$ is the disjoining pressure, $\sigma$ is the surface tension, $K$ is the curvature, herein $K \approx \partial^{2} \delta / \partial x^{2}$, and $\Im$ is the electrostatic field term.

The electric field is determined by solving Laplace's equation:

$\nabla^{2} \phi=0$

where $\phi(x, y)$ is the electric potential. The boundary conditions are

$\phi(x, 0)=0 \quad$ and $\quad \phi(x, \hat{H})=F \hat{H} \Phi(x)$

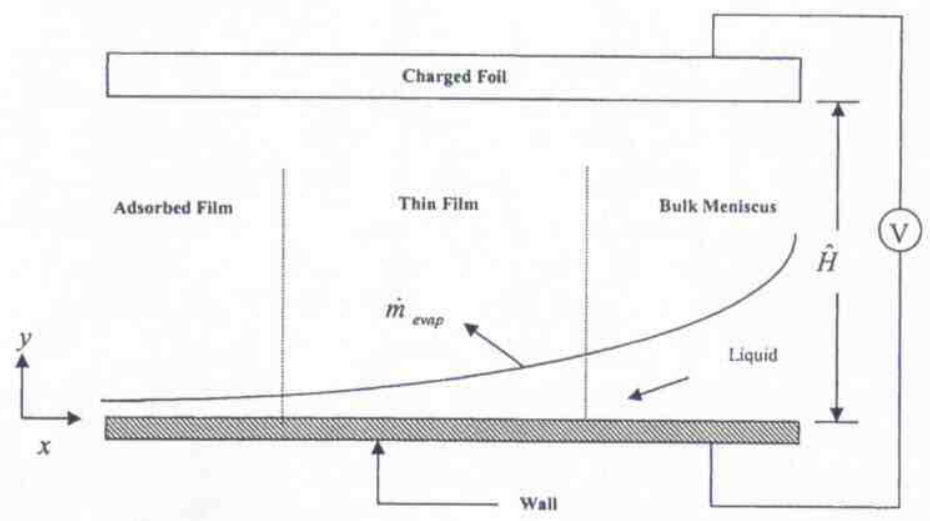

Figure 1. The geometry of an evaporating interface. 
Herein, assume $\Phi(x)=1$.

As a result, the electrostatic field term is obtained as follows:

$\Im=\left[-\frac{1}{8 \pi} \varepsilon E^{2}\right]_{v}-\left[-\frac{1}{8 \pi} \varepsilon E^{2}\right]_{f}=\frac{\varepsilon_{v} F^{2}}{8 \pi}\left(\frac{\varepsilon_{v}}{\varepsilon_{f}}-1\right)\left[1+\left(\frac{\delta_{o}}{x_{o}}\right)^{2}\left(\frac{\partial \eta}{\partial X}\right)^{2}\right]$

where $E^{2}=E_{x}^{2}+E_{y}^{2}$ and $\varepsilon_{f} E_{f}=\varepsilon_{v} E_{v}, E_{x}$ is the electric field in $x$ direction $=-\left(\frac{\partial \phi}{\partial x}\right), E_{y}$ is the electric field in $y$ direction $=-\left(\frac{\partial \phi}{\partial y}\right), \varepsilon$ is electric permittivity $=\gamma \varepsilon_{o}, \varepsilon_{o}$ is electric permittivity of free space $=8.854 \times$ $10^{12} \mathrm{~F} / \mathrm{m}, \varepsilon_{f}, \varepsilon_{v}$ are electric permittivity of liquid and vapor, respectively, $E_{f}, E_{v}$ are the electric field in liquid and vapor at the interface, respectively, $\gamma$ is the dielectric constant, and

$F$ is the electric field strength $=V / \hat{H}$.

Following Wayner (1994), the evaporative mass flux as a function of the temperature and pressure at the interface is given based on the Kelvin-Claypeyron equation as the following expression:

$\dot{m}_{\text {evap }}=a\left(T_{\ell v}-T_{v}\right)+b\left(P_{\ell}-P_{v}\right)$

where $\dot{m}_{\text {evap }}$ is the evaporative flux, defined as the amount of liquid evaporating from the liquid film per unit area per unit time, $T_{\ell_{v}}$ is the temperature of the liquid-vapor interface, $T_{v}$ is the temperature of the vapor, and the coefficients $a$ and $b$ are defined as

$a=C_{1}\left(\frac{M}{2 \pi R T_{\ell v}}\right)^{1 / 2} \cdot\left(\frac{P_{v} M \Delta h_{m}}{R T_{v} T_{\ell v}}\right)$

$b=C_{1}\left(\frac{M}{2 \pi R T_{\ell v}}\right)^{1 / 2} \cdot\left(\frac{V_{\ell} P_{v}}{R T_{\ell v}}\right)$

where $C_{1}$ is the accommodation coefficient, $M$ is the liquid molecular weight, $R$ is the universal gas constant, $P_{v}$ is the bulk vapor pressure of the liquid at $T_{v}, V_{\ell}$ is the molar volume of the liquid at $T_{\ell v}$, and $\Delta h_{m}$ is the liquid enthalpy of vaporization per unit mass at $T_{\ell v}$.

The dynamics of the liquid flow in the thin film may be approximated by the lubrication theory of fluid mechanics as a boundary layer-type approximation, thus 
$\mu_{\ell} \frac{\partial^{2} u}{\partial y^{2}}=\frac{d P_{\ell}}{d x}$

using no shear stress condition at $y=\delta,(\partial u / \partial y)=0$, and no-slip condition at the wall $u=0$. The velocity distribution in the film, $u$, is given by

$u(y)=\frac{1}{\mu_{\ell}} \cdot \frac{d P_{\ell}}{d x} \cdot\left(\frac{y^{2}}{2}-y \cdot \delta\right)$

Using the velocity profile given by Equation (7), the mass flow rate across an area of height $\delta$ and unit width is obtained as

$\Gamma=\frac{\rho_{\ell}}{\mu_{\ell}} \cdot \frac{d P_{\ell}}{d x} \cdot \int_{0}^{\delta}\left(\frac{y^{2}}{2}-y \delta\right) d y=-\frac{\delta^{3}}{3 v_{\ell}} \cdot \frac{d P_{\ell}}{d x}$

Applying conservation of mass within the thin film, which requires that the reduction in the liquid flow rate equals the evaporation rate; the evaporative flux is given by

$\frac{d \Gamma}{d x}=-\dot{m}_{\text {evap }}$

For the isothermal interfacial condition, the evaporative flux will not depend locally upon the interface temperature. Therefore, it is not necessary to include the energy equation to solve for the temperature field.

The following dimensionless variables are defined to make all governing equations in dimensionless form:

$$
\begin{aligned}
& \eta=\delta / \delta_{o} \quad X=x / x_{o} \quad \Delta T=T_{w}-T_{v} \\
& \psi_{d}=\psi / \psi_{o} \quad \psi=A \delta^{-3} \quad \psi_{o}=\frac{a}{b} \Delta T \\
& C a=\frac{\mu_{\ell} u_{o}}{\sigma} \quad x_{o}=\left(\frac{\sigma \delta_{o}}{\psi_{o}}\right)^{1 / 2} \quad K=\frac{d^{2} \delta}{d x^{2}} \\
& \dot{m}_{i d}=\rho_{\ell} u_{o}=a\left(T_{w}-T_{v}\right)=a \Delta T
\end{aligned}
$$


where $\mathrm{Ca}$ is the capillary number, $\dot{m}_{i d}$ is ideal evaporative flux based upon a flat liquid-vapor interface with no disjoining pressure, $u_{o}$ is the reference velocity of the liquid, $x_{o}$ is the reference length of the thin film, $\psi_{o}$ is the disjoining pressure of the adsorbed film, and $\delta_{o}$ is the adsorbed film thickness. For nearly perfect wetting and organic nonpolar liquids, the disjoining pressure is given by $\psi=A \delta^{-3}$, where $A$ is a constant related to the Hamaker constant.

Using the dimensionless variables defined in Equation (10), the governing equations yield the following dimensionless fourth-order ordinary differential equation for the interfacial shape of the thin film:

$$
\left\{\eta^{3}\left(\psi_{d}^{\prime}+\eta^{\prime \prime \prime}+\frac{\Im^{\prime}}{\psi_{o}}\right)\right\}^{\prime}=-\frac{3 \cdot C a}{\left(\frac{\psi_{o} \delta_{o}}{\sigma}\right)^{2}}\left(1-\psi_{d}-\eta^{\prime \prime}-\frac{\Im}{\psi_{o}}\right)
$$

with initial condition at $X=0: \quad \eta=\eta_{a}, \quad \eta^{\prime}=\eta_{a}^{\prime}, \quad \eta^{\prime \prime}=\eta_{a}^{\prime \prime}$, and $\eta^{\prime \prime \prime}=\eta_{a}^{\prime \prime \prime}$.

The four boundary conditions required to solve Equation (11) are to be stated in a way that forces the asymptotic curvature of the thin film to be the same as the curvature of the meniscus and to correspond to the boundary conditions at the adsorbed film region established by $\eta=\eta_{a}, \eta^{\prime}=\eta^{\prime \prime}=\eta^{\prime \prime \prime}=0$. In addition to the interline region, which is characterized by negligible curvature, the curvature terms in Equation (11) set to be zero. The differential equation that governs the interfacial profile in the interline region becomes

$$
\left\{\eta^{3}\left(\psi_{d}^{\prime}+\frac{\Im^{\prime}}{\psi_{o}}\right)\right\}^{\prime}=-\frac{3 \cdot C a}{\left(\frac{\psi_{o} \delta_{o}}{\sigma}\right)^{2}}\left(1-\psi_{d}-\frac{\Im}{\psi_{o}}\right)
$$

The boundary conditions for Equation (12) may written as:

$$
\eta=1+\gamma \text { and } \eta^{\prime}=\epsilon \text { at } \quad X \approx 0
$$

The parameter $\gamma$ depends on the evaporation rate as shown in Wayner's experiments, and Dussan et al. have postulated the interline slope, $\epsilon$, to be only fluid-solid dependent and independent of the thin film and the meniscus region.

As a result, the four boundary conditions for Equation (12) will be specified as follows:at $X=0: \quad \eta=1+\gamma, \quad \eta^{\prime}=\epsilon, \quad \eta^{\prime \prime}=\eta_{a}^{\prime \prime}, \quad \eta^{\prime \prime \prime}=0$. 


\section{RESULTS AND DISCUSSION}

In this study, ammonia is employed as a working liquid. The temperature at the plate is a nearly constant temperature of $50^{\circ} \mathrm{C}$. The vapor temperature is assumed to be approximately the same as the plate temperature. The difference between the interfacial temperature and the vapor temperature is $0.0006 \mathrm{~K}$.

The dimensionless interfacial shape of the thin film is a fourth-order nonlinear ordinary differential equation and is treated as an initial value problem. We have used the fifth-order Runge-Kutta-Fehlberg method to solve Equations (11) and (12).

In the present study, the solution of the nonlinear ordinary differential equations yields the interfacial shape of the thin film as a function of the length of the thin film. The sequential solutions are pressure gradient distribution, $\frac{d P_{t}}{d x}$, evaporative mass flux, $\dot{m}_{e v a p}$, convective heat flux, $\dot{q}_{c o n v}^{\prime \prime}$, conductive heat flux, $\dot{q}_{c o n d}^{\prime \prime}$, and heat transfer coefficient, $h_{\text {coeff }}$, within the thin film as the following expressions:

$$
\begin{aligned}
& \frac{d P_{\ell}}{d x}=-\frac{\psi_{o}^{3 / 2}}{\left(\sigma \delta_{o}\right)^{1 / 2}}\left(\psi_{d}^{\prime}+\eta^{\prime \prime \prime}+\frac{\Im^{\prime}}{\psi_{o}}\right) \\
& \dot{m}_{\text {evap }}=-\frac{\left(\delta_{o} \psi_{o}\right)^{2}}{3 v_{\ell} \sigma}\left\{\eta^{3} \psi_{d}^{\prime}+\eta^{3} \eta^{\prime \prime \prime}+\frac{\eta^{3} \Im^{\prime}}{\psi_{o}}\right\}^{\prime} \\
& \dot{q}_{\text {conv }}^{\prime \prime}=\dot{m}_{\text {evap }} \Delta h_{m} \\
& \dot{q}_{\text {cond }}^{\prime \prime}=-k \nabla T \\
& h_{\text {coeff }}=\frac{\dot{q}_{\text {conv }}^{\prime \prime}}{\Delta T}
\end{aligned}
$$

Under isothermal interfacial condition, Figure 2 represents the effect of the electrostatic field on the interfacial shape of the thin evaporating film in terms of dimensionless thin film thickness, $\eta$. The results indicate that the curvature of the thin film decreases as the electric field strength increases.

Figure 3 provides the pressure gradient distribution of the liquid in the thin film along the length of the thin film. Figure 4 illustrates that the evaporative mass flux increases as the electric field strength increases. An increase in the electric field strength decreases the film thickness, increases the pressure gradient along the thin film, and augments the evaporative mass flux. The increase in the pressure gradient increases the disjoining 


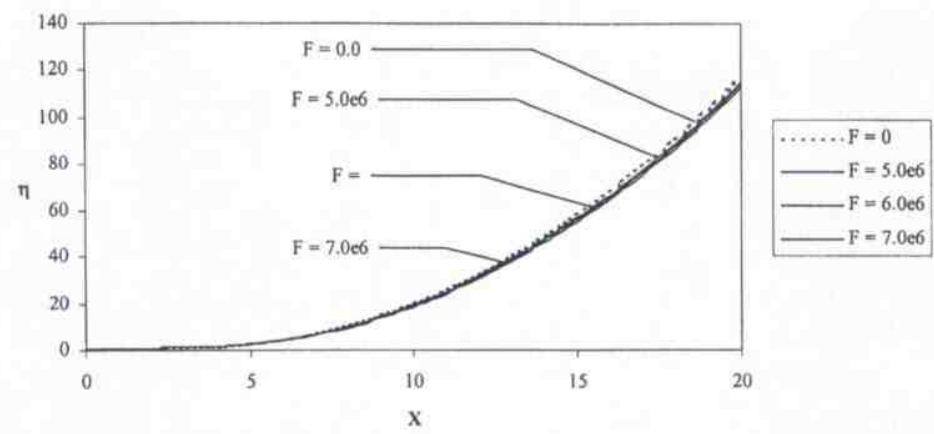

Figure 2. Dimensionless thin film thickness profiles in the thin film.

pressure in the thin film. This causes an increase in the liquid flow from the bulk of the meniscus region to the thin film in order to maintain steady-state operation. As a result, the evaporative mass flux in the thin film region increases, as shown in Figure 4. Since convective heat flux is related to the evaporative mass flux as shown in Equation (15), the profile of the convective heat flux in the thin film has the same trend as the evaporative flux profile as shown in Figure 5; the conductive heat flux is shown in Figure 6.

The convective heat flux along the length of the thin film increases as the electric field strength increases. Since the temperature difference between the wall and the vapor phase of the liquid is defined as a constant, the heat transfer coefficient at the interface is related only to convective heat fluxes as shown in Equation (17).

Figure 7 shows that the heat transfer coefficient in the thin film region increases when the electric field strength increases. Consider all the results, it can be stated that application of the electric field on the thin film can augment the heat transfer coefficient in the thin film.

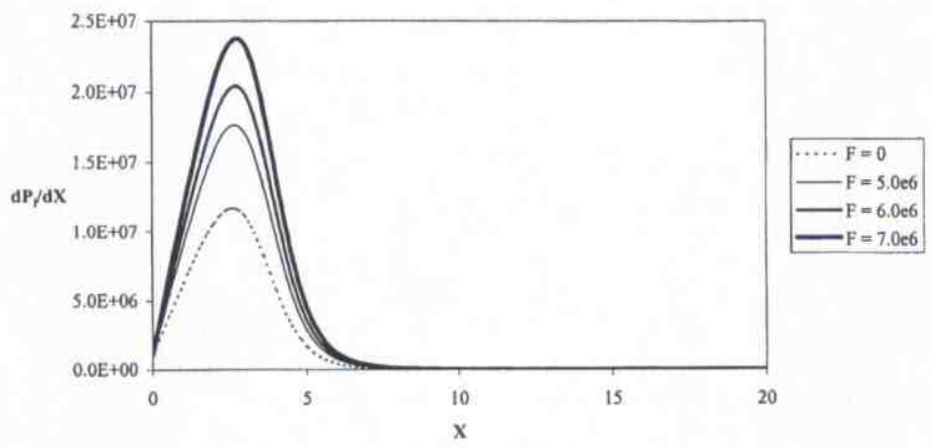

Figure 3. Pressure gradient distributions in the thin film. 


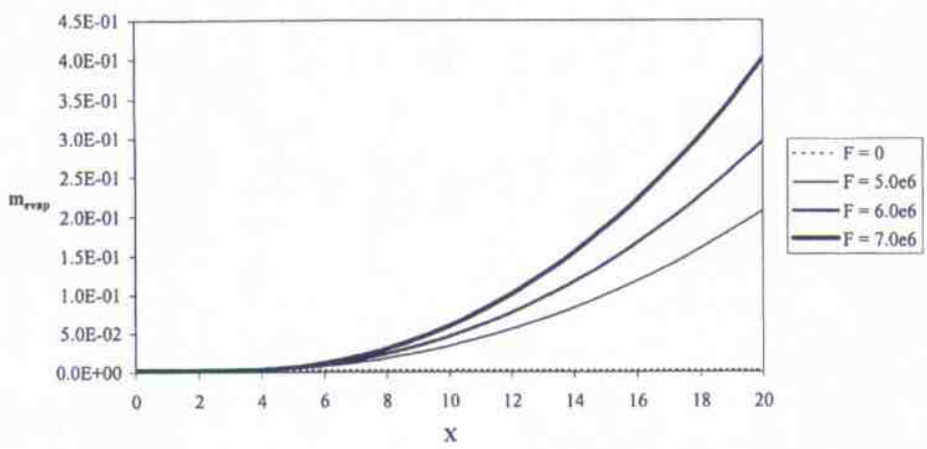

Figure 4. Evaporative flux profiles in the thin film.

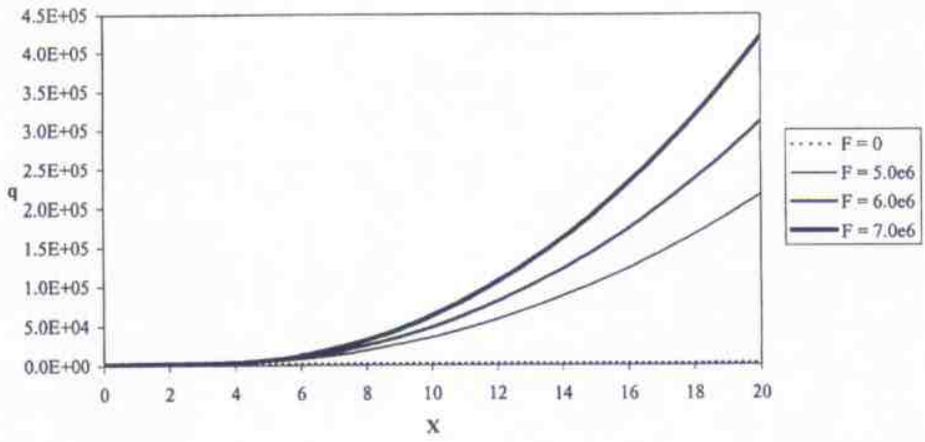

Figure 5. Convective heat flux profiles in the thin film.

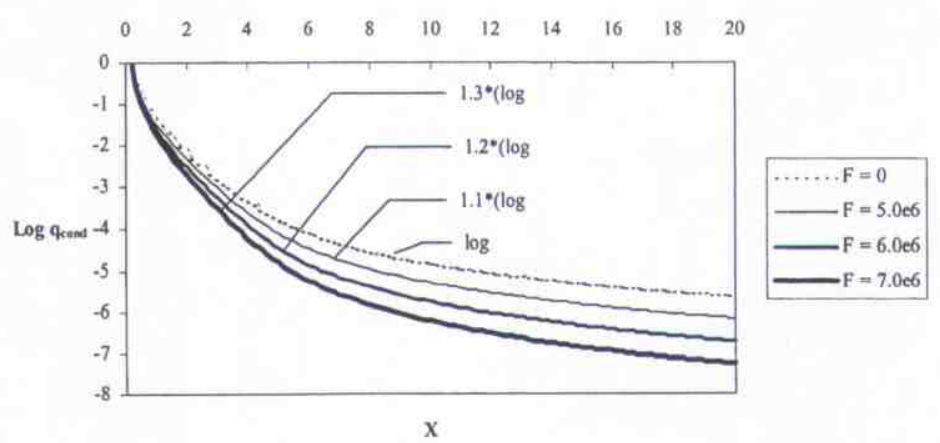

Figure 6. Conductive heat flux profiles in the thin film. 


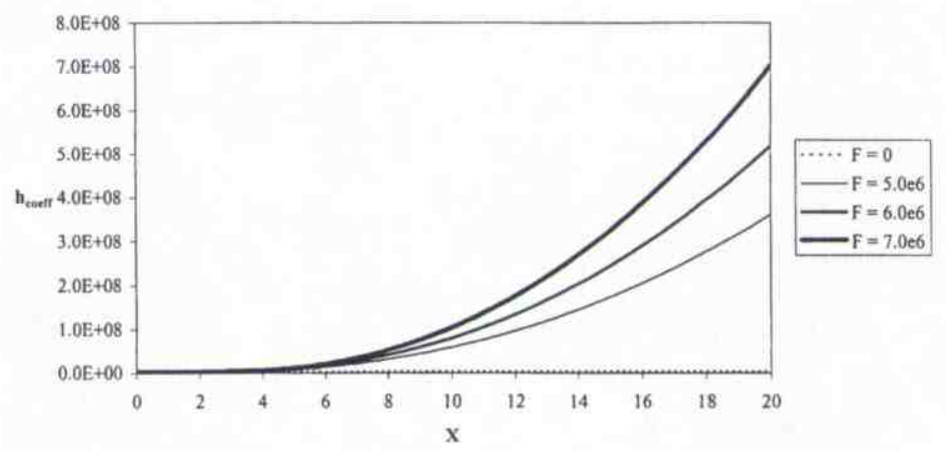

Figure 7. Heat transfer coefficient profiles in the thin film.

\section{CONCLUDING REMARKS}

In the present study, a new mathematical model is presented to investigate the effect of the electrostatic field on an evaporating thin liquid film under isothermal interfacial condition. The results indicate that utilization of the electric field can significantly enhance heat transfer in an evaporating thin liquid film. The heat transfer coefficient increases as the electric field strength increases. They also indicate that application of the electric fields on the evaporating film will be a way to expand the extended meniscus region to attain high heat transfer coefficients and high heat flux densities. Finally, the results obtained by the model without applying the electric field are in good agreement with those published in the literature.

\section{NOMENCLATURE}

A Hamaker constant, J

$a, b \quad$ coefficient parameter

$C_{1}$ accommodation coefficient

$\mathrm{Ca}$ capillary number

$E_{x}$ dimensionless electric field in $x$-direction at interface

$E_{y}$ dimensionless electric field in $y$-direction at interface

$F \quad$ electric field strength, $\mathrm{V} \cdot \mathrm{m}^{-1}$

$\hat{H}$ distance between a charged foil and the plate, $\mathrm{m}$

$\Delta h_{m} \quad$ latent heat of vaporization of the liquid, $\mathrm{J} \cdot \mathrm{Kg}^{-1}$

$h_{\text {coeff }}$ heat transfer coefficient, $\mathrm{W} \cdot \mathrm{m}^{-2} \cdot \mathrm{K}-1$

$k$ thermal conductivity, $\mathrm{W} \cdot \mathrm{m}^{-1} \cdot \mathrm{K}^{-1}$

$K \quad$ curvature of the interface, $\mathrm{m}^{-1}$

$L \quad$ length of the plate, $\mathrm{m}$

$M \quad$ liquid molecular weight, $\mathrm{Kg} \cdot \mathrm{mol}^{-1}$

$\dot{m}_{\text {evap }}$ evaporative mass flux, $\mathrm{Kg} \cdot \mathrm{m}^{-2} \cdot \mathrm{K}^{-1}$

$\dot{m}_{i d}$ ideal evaporative mass flux, $\mathrm{Kg} \cdot \mathrm{m}^{-2} \cdot \mathrm{K}^{-1}$

$P \quad$ pressure $\mathrm{Pa}$

$\dot{q}^{\prime \prime} \quad$ heat flux, $\mathrm{W} \cdot \mathrm{m}^{-2}$ 
$R \quad$ universal gas constant, $\mathrm{J} \cdot \mathrm{mol}^{-1} \cdot \mathrm{K}^{-1}$

$T$ temperature, $\mathrm{K}$

$\Delta T \quad$ temperature difference, $\mathrm{K}$

$u \quad$ velocity component in $x$ direction, $\mathrm{m} \cdot \mathrm{s}^{-1}$

$U_{o} \quad$ reference velocity, $\mathrm{m} \cdot \mathrm{s}^{-1}$

$V \quad$ voltage (volt)

$V_{\ell}$ molar volume of the liquid, $\mathrm{m}^{3} \cdot \mathrm{mol}^{-1}$

$x, y$ coordinate directions parallel and perpendicular to the plate, $\mathrm{m}$

$x_{o} \quad$ reference length of the thin film, $\mathrm{m}$

Greek Letters

$\delta \quad$ thin film thickness, $\mathrm{m}$

$\varepsilon \quad$ electric permittivity, $\mathrm{C}^{2} \cdot \mathrm{N}^{-1} \cdot \mathrm{m}^{-2}, \mathrm{~F} \cdot \mathrm{m}^{-1}$

$\gamma \quad$ dielectric constant

$\varepsilon_{o} \quad$ electric permittivity of free space, $\mathrm{C}^{2} \cdot \mathrm{N}^{-1} \cdot \mathrm{m}^{-2}, \mathrm{~F} \cdot \mathrm{m}^{-1}$

3 electrostatic parameter

$\psi \quad$ disjoining pressure, $\mathrm{Pa}$

$\psi_{d} \quad$ dimensionless disjoining pressure

$\rho \quad$ density, $\mathrm{Kg} \cdot \mathrm{m}^{-3}$

$\mu \quad$ absolute viscosity, $\mathrm{Kg} \cdot \mathrm{m}^{-1} \cdot \mathrm{s}^{-1}$

$v \quad$ kinematic viscosity of liquid, $\mathrm{m}^{2} \cdot \mathrm{s}^{-1}$

$\Gamma \quad$ mass flow rate per unit width, $\mathrm{Kg} \cdot \mathrm{m}^{-1} \cdot \mathrm{s}^{-1}$

$\eta \quad$ dimensionless thin film thickness

$X$ dimensionless length of the thin film in $x$-direction

$\sigma \quad$ surface tension, $\mathrm{N} \cdot \mathrm{m}^{-1}$

$\phi \quad$ electric potential, $\mathrm{V}$

Subscripts

$f \quad$ fluid

$\ell \quad$ liquid phase

$v \quad$ vapor phase

$\ell v \quad$ liquid-vapor interface

$\omega \quad$ at the plate

$o \quad$ at the adsorbed film region

\section{REFERENCES}

Barletta, A. and Zanchini, E. (1995). The temperature field in a cylindrical electric conductor with annular section, Int. J. Heat Mass Transfer, 38(15), $2821-2832$.

Berghmans, J. (1976). Electrostatic fields and the maximum heat flux, Int. J. Heat Mass Transfer, 19, 791-797.

Brown, J. R., Chang, W. S., Hallinan, K. P., and Chebaro, H. C. (1993). Heat transfer from stable, evaporating thin films in the neighborhood of a contact line, ASME, 93-HT-4, 1-8.

Chebaro, H. C. and Hallinan, K. P. (1993). Boundary conditions for an evaporating thin film for isothermal interfacial conditions, J. Heat Transfer, 115, $816-819$. 
Chebaro, H. C., Hallinan, K. P., Kim, S. J., and Chang, W. S. (1992). Evaporation from a porous wick heat pipe for isothermal interfacial conditions, ASME, HTD-Vol. 221, 23-28.

Chebaro, H. C., Hallinan, K. P., Kim, S. J., and Chang, W. S. (1993). Evaporating from a porous wick heat pipe for non-isothermal interfacial conditions, ASME, 93-HT-6, 1-8.

Chebaro, H. C., Hallinan, K. P., Kim, S. J., and Chang, W. S. (1994). Evaporating from an extended meniscus for non-isothermal interfacial conditions, J. Thermophysics Heat Transfer, 8(4), 709-716.

Dasgupta, S., Schonberg, J. A., Kim, I. Y., and Wayner, Jr., P. C. (1993). Use of the augmented Young-Laplace equation to model equilibrium and evaporating extended menisci, J. Colloid Interface Sci., 157, 332-342.

Dasgupta, S., Kim, I. Y., and Wayner, Jr., P. C. (1994). Use of the KelvinClapeyron equation to model an evaporating curved microfilm, J. Heat Transfer, 116, 1007-1015.

Dussan, E. B., Rame, E., and Garoff, S. (1991). On identifying the appropriate boundary conditions at a moving contact line: An experimental investigation, J. Fluid Mech., 230, 97-116.

Edwards, D. K., Balakrishnan, A., and Catton, I. (1974). Power-law solutions for evaporation from a finned surface, J. Heat Transfer, August 423-425.

Gorla, R. S. R. and Byrd, L. W. (1999). Effect of electrostatic field on film rupture, J. Fluids Eng., 121, 1-7.

Ha, J. M. and Peterson, G. P. (1998). The heat transport capacity of micro heat pipes, J. Heat Transfer, 120, 1064-1071.

Holm, F. W. and Goplen, S. P. (1979). Heat transfer in the meniscus thin-film transition region, J. Heat Transfer, 101, 543-547.

Hopkins, R. Faghri, A., and Khrustalev, D. (1999). Flat miniature heat pipes with micro capillary grooves, J. Heat Transfer, 121, 102-109.

Jones, T. B. (1978). Electrohydrodynamically enhanced heat transfer in liquidA review, Adv. Heat Transfer, 14, 107-148.

Khrustalev, D. and Faghri, A. (1995). Thermal characteristics of conventional and flat miniature axially grooved heat pipes, J. Heat Transfer, 117, $1048-1054$.

Kim, I. Y. and Wayner, Jr., P. C. (1996). Shape of an evaporating completely wetting extended meniscus, J. Thermodynamics Heat Transfer, 10(2), $320-325$.

Lazarenko, B. R., Grosu, F. P., and Bologa, M. K. (1975). Convective heattransfer enhancement by electric fields, Int. J. Heat Mass Transfer, 18, 1433-1441.

Lykoudis, P. S. and Yu, C. P. (1963). The influence of electrostrictive forces in natural thermal convection, Int. J. Heat Mass Transfer, 6, 853-862.

Maekawa, T., Abe, K. and Tanasawa, I. (1992). Onset of natural convection under an electric field, Int. J. Heat Mass Transfer, 35(3), 613-621. 
Mirzamoghadam, A. and Catton, I. (1988). A physical model of the evaporating meniscus, J. Heat Transfer, 110, 201-207.

Moctar, A. O. E., Peerhossaini, H., Peurian, P. L., and Bardon, J. P. (1993). Ohmic heating of complex fluids, Int. J. Heat Mass Transfer, 36(12), 3143-3152.

Moosman, S. and Homsy, G. M. (1980). Evaporating menisci of wetting fluids, J. Colloid Interface Sci., 73(1), 212-223.

Neve, R. S. and Yan, Y. Y. (1996). Enhancement of heat transfer performance using combined electrohydrodynamic and passive methods, Int. J. Heat Fluid Flow, 17, 403-409.

Pismen, L. M., Rubinstein, Boris Y., and Bazhlekov, Ivan (2000). Spreading of a wetting film under the action of van der Waals forces, Phys. Fluids, 12(3), $480-483$.

Potash, Jr., M. and Wayner, Jr., P. C., (1972). Evaporation from a two-dimensional extended meniscus, Int. J. Heat Mass Transfer, 15, 1851-1863.

Renk, F., Wayner, Jr., P. C., and Homsy, G. M. (1978). On the transition between a wetting film and a capillary meniscus, J. Colloid Interface Sci., 67(3), 408-414.

Schonberg, J. A. and Wayner, P. C. Jr., (1992). Analytical solution for the integral contact line evaporating heat sink, J. Thermophysics, 6(1), 128-134.

Stephan, P. C. and Busse, C. A. (1992). Analysis of the heat transfer coefficient of grooved heat pipe evaporator walls, Int. J. Heat Mass Transfer, 35(2), $383-391$.

Swanson, L. W. and Herdt, G. C. (1992). Model of the evaporating meniscus in a capillary tube, J. Heat Transfer, 114, 434-441.

Swanson, L. W. and Peterson, G. P. (1994). Evaporating extended meniscus in a V-shaped channel, J. Thermophys. Heat Transfer, 8(1), 172-180.

Takano, K., Tanasawa, I., and Nishio, S. (1994). Active enhancement of evaporation of a liquid drop on a hot solid surface using a static electric field, Int. J. Heat Mass Transfer, 37, 65-71.

Tao, Y. X. and Kaviany, M. (1991). Simultaneous heat and mass transfer from a two-dimensional, partially liquid-covered surface, J. Heat Transfer, 113, $874-882$.

Truong, J. G. and Wayner, Jr., P. C. (1987). Effects of capillary and van der Waals dispersion forces on the equilibrium profile of a wetting liquid: Theory and experiment, J. Chem. Phys., 87(7), 4180-4188.

Turnbull, R. J. (1971). Effect of a non-uniform alternating electric field on the thermal boundary layer near a heated vertical plate, J. Fluid Mech., 49, 693-703.

Voinov, O. V. (1998). Meniscus contact angle in unsteady viscous flow, J. Colloid Interface Sci., 201, 93-102.

Wayner, Jr., P. C. (1989). A dimensionless number for the contact line evaporative heat sink, J. Heat Transfer, 111, 813-815. 
Wayner, Jr., P. C. (1994). Thermal and mechanical effects in the spreading of a liquid film due to a change in the apparent finite contact angle, J. Heat Transfer, 116, 938-945.

Wayner, Jr., P. C., Kao, Y. K., and Lacroix, L. V. (1976). The interline heattransfer coefficient of an evaporating wetting film, Int. J. Heat Mass Transfer, 19, 487-492.

$\mathrm{Xu}, \mathrm{X}$. and Carey, V. P. (1990). Film evaporation from a micro-grooved surface-An approximate heat transfer model and its comparison with experimental data, J. Thermophys. 4(4), 512-520.

Yabe, A. (1991). Active heat transfer enhancement by applying electric fields, in Proceedings of the ASME/ JSME Thermal Engineering Conference, 3, $\mathrm{xv}-\mathrm{xxiii}$.

Yabe, A. (1995). Heat engineering, in Handbook of Electrostatic Processes, Marcel Dekker, New York, 555-580.

Zaghdoudi, M. C. and Lallemand, M. (1999). Analysis of the polarity influence on nucleate pool boiling under DC electric field, J. Heat Transfer, 121, $856-864$.

Post-print standardized by MSL Academic Endeavors, the imprint of the Michael Schwartz Library at 